\title{
Chromosome mapping of Rett syndrome: a likely candidate region on the telomere of $\mathrm{Xq}$
}

Fengqing Xiang, Zhiping Zhang, Angus Clarke, Pereira Joseluiz, Naidu Sakkubai, Budden Sarojini, Celia D Delozier-Blanchet, Ingo Hansmann, Lars Edström, Maria Anvret

Department of

Molecular Medicine, Karolinska Hospital, S-17176 Stockholm, Sweden

F Xiang

Z Zhang

M Anvret

Department of Clinical

Neuroscience,

Karolinska Hospital,

S-17176 Stockholm,

Sweden

F Xiang

L Edström

M Anvret

Department of Medical Genetics and Psychological

Medicine, University of Wales College of Medicine, Cardiff CF4 4XN, UK

A Clarke

Parana State General Hospital, Av Iguacu, 3983 Curitiba/Parana, Brazil

$P$ Joseluiz

Kennedy Krieger Institute, 707 North

Broadway, Baltimore, Maryland 21205, USA N Sakkubai

Oregon Health

Sciences University,

PO Box 574, Portland, Oregon 97207 , USA

B Sarojini

Department of Medical Genetics, Cantonal Hospital, Geneva University, Switzerland

C D Delozier-Blanchet

Institute of Human Genetics, Göttingen University,

Gosslerstrasse 12d, D-37073 Göttingen, Germany

I Hansmann

Correspondence to:

Dr Anvret.

Received 10 June 1997 Revised version accepted for publication 16 September 1997

\begin{abstract}
Rett syndrome (RS) is a disease of neurological development. First reported 30 years ago in 1966, its biological and genetic basis remains obscure. $R S$ is commonly thought of as an $\mathrm{X}$ linked dominant disorder lethal to hemizygous males. The few familial cases would arise through mosaicism or because of occasional females failing to manifest the disorder through skewed $X$ inactivation in relevant cell types. We have one family where the mother and daughter are affected with RS, and which can be explained according to this hypothesis. If the alternative proposal of Thomas (1996) is correct, that the lack of males affected by such disorders is the result of a high male to female ratio of germline mutations rather than of gestational lethality, then the RS gene should be located on the grandpaternal chromosome. Genomic screening with markers covering the whole $X$ chromosome has been performed. Studies using multiple informative markers indicate that the RS locus is likely to be located close to one of the $X$ chromosome telomeres. Further investigations in eight additional families suggest the most likely region for the $R S$ gene to be is the distal part of Xq (Xq28).

$(\mathcal{M}$ Med Genet 1998;35:297-300)
\end{abstract}

Keywords: Rett syndrome; gene mapping; X chromosome

Rett syndrome (RS) is a disease of neurological development. The clinical signs are thought to result from the effects of an arrest in development of the brain. ${ }^{1}$ Affected subjects exhibit hypotonia, autistic-like behaviour, stereotypic hand movements, loss of purposeful hand use, mental retardation, and disturbance of sleep and breathing. The disease affects exclusively females with a prevalence of 1 in 10000 15000 . Symptoms usually appear at 6 to 18 months or later. A very few males with a phenotypic picture similar to RS have been reported, but none has been accepted as having the same disease entity. Since only females have been diagnosed so far, an $\mathrm{X}$ linked dominant mode of inheritance with lethality in males has been suggested. The sex ratio within the families of affected females is normal and there is no evidence of an increased frequency of miscarriages. Most cases are sporadic and are thought to arise as new mutations. There are too few familial cases, with presumed female carriers or mosaics, for evidence of a disturbed sex ratio to have accumulated.

The cause of Rett syndrome is unknown. Chromosomal abnormalities have been reported: translocations $\mathrm{t}(\mathrm{X} ; 22)(\mathrm{p} 11.22 ; \mathrm{p} 11)^{2}$ and $\mathrm{t}(\mathrm{X} ; 3)(\mathrm{p} 22.1 ; \mathrm{q} 13.31),{ }^{3}$ deletions $\operatorname{del}(3)$ (3p25.1-p25.2) ${ }^{4}$ and del(13)(13q12.1-q21.2), RS with fragile $\mathrm{X},{ }^{6}$ and RS with Down's syndrome. ${ }^{7}$ No concordance for the chromosomal abnormalities has been found, however, since different abnormalities are involved in each case.

Recently, Thomas ${ }^{8}$ proposed an alternative explanation for the lack of affected males in RS and other $\mathrm{X}$ linked dominant diseases with apparent gestational lethality in affected males. He suggested that it may be the result of a high male to female ratio of germline mutations. We have one family where the mother and daugh-

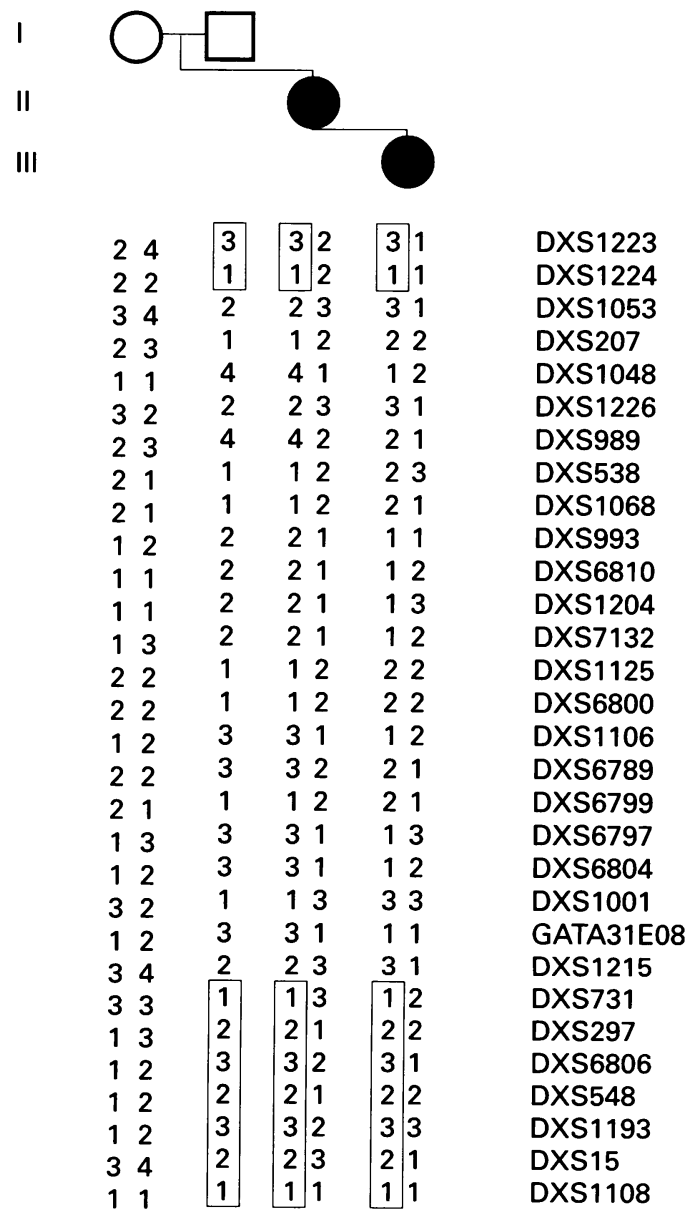

Figure $1 X$ chromosome haplotype analysis in family 1. Closed boxes show the grandpaternal origin of the $X$ chromosome. 


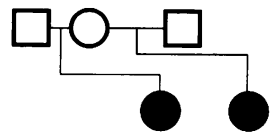

(2)

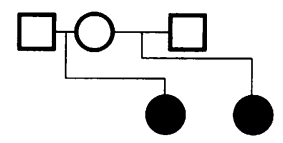

(3)

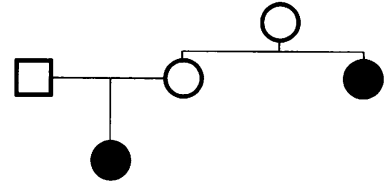

(4)

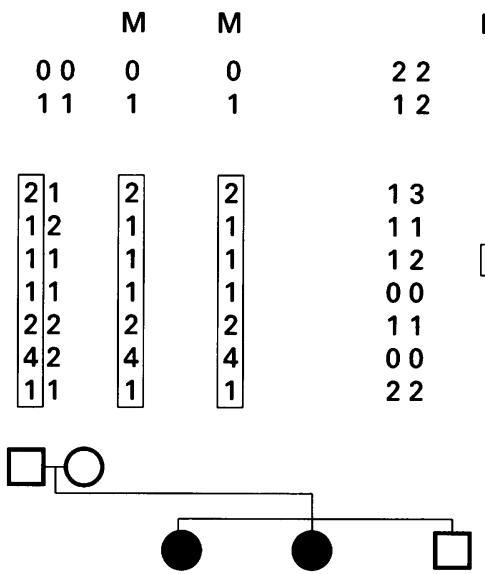

(5)

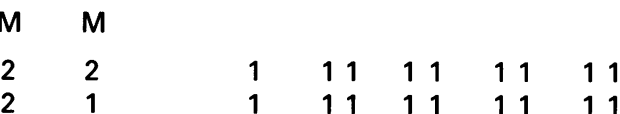

$12 \quad 21 \quad 00 \quad 21$

$\begin{array}{lllll}41 & 21 & 13 & 21\end{array}$

$\begin{array}{lllllll}4 & 3 & 2 & 12 & 3 & 2\end{array}$

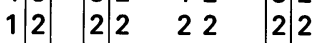

\begin{tabular}{ll|l|llllll}
3 & 4 & 4 & 1 & 1 & 2 & 4 & 1
\end{tabular}

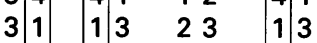

\begin{tabular}{l|l|l|lllll}
2 & 3 & 1 & 1 & 1 & 3 & 1
\end{tabular}
Marker

DXS1223

DXS1224

DXS731

DXS297

DXS6806

DXS548

DXS1193

DXS15

DXS1108

Figure 2 Pedigrees and haplotypes of families 2-9. Concordant regions of the maternal $X$ chromosome are showed in boxes.

ter are affected. According to Thomas's hypothesis, the affected mother in this family might have received a new mutation on the $X$ chromosome from her father and the affected daughter must have inherited the same chromosomal region with the mutant gene from her. Therefore, identifying the regions of the $\mathrm{X}$ chromosome in the affected daughter that derive from the grandpaternal $\mathrm{X}$ chromosome would indicate the location of the defective gene. In order to investigate this, we have completely screened the whole $\mathrm{X}$ chromosome in this family with 60 microsatellite markers. This analysis showed that the affected mother only transmitted the telomeric regions of the grandpaternal X chromosome to the affected daughter. In addition to this family, eight more RS families were further screened for concordance of the maternal $\mathrm{X}$ chromosome telomeric regions in order to refine the candidate region for the RS gene.

\section{Materials and methods}

Nine "RS families", with at least two closely related females affected by classical RS, were investigated in this study. In family 1 , the 
mother and daughter are affected. In families 2 and 3 two half sisters with the same mother are affected. In family 4 , an aunt and her niece are affected. In families 5-8, there are two affected full sisters. There are three RS girls (full sisters) in family 9, which is the only family so far reported with more than two affected girls. The diagnostic criteria we used were those of the Rett Syndrome Diagnostic Criteria Work Group. ${ }^{9}$

The microsatellite markers that we used (CHLC Human Screening Set/Weber Version 6 , Research Genetics, Inc) are distributed in 1-8 cM intervals on the $\mathrm{X}$ chromosome. Genomic DNA was isolated from peripheral blood or EBV transformed lymphoblastoid cell lines by conventional methods. PCR amplification was carried out in a total volume of $10 \mu \mathrm{l}$ with $50 \mathrm{ng}$ of DNA and $2 \mathrm{pmol}$ of each primer labelled with ${ }^{33} \mathrm{P}$. The PCR cycle conditions were: $95^{\circ} \mathrm{C}$ for five minutes, followed by 35 cycles of $95^{\circ} \mathrm{C}$ for one minute, $55-60^{\circ} \mathrm{C}$ for approximately one minute (depending on the particular primers), and $72^{\circ} \mathrm{C}$ for one minute, with a final extension of $72^{\circ} \mathrm{C}$ for seven minutes. The PCR samples were separated on $6 \%$ denaturing polyacrylamide gels and the alleles were detected by autoradiography.

\section{Results}

We screened the $\mathrm{X}$ chromosomes in family 1 with 60 microsatellite markers. Half of the 60 markers (50\%) were informative. Haplotype analysis indicated that the affected daughter inherited only the most telomeric parts of the X chromosome from her grandfather (fig 1), the regions distal to DXS1053 on Xp and distal to DXS1215 on Xq. According to Thomas's hypothesis, the RS gene should be located in a region of grandpaternal origin. ${ }^{8}$ In order to further confirm and refine these potential RS gene candidate regions, eight additional RS families were used to identify areas of concordance in the affected females for their maternally derived X chromosomes.

The $\mathrm{Xp}$ telomeric region and the greater part of the $\mathrm{Xq}$ telomeric region were discordant or uninformative in these eight additional families. Only one subregion within the $\mathrm{Xq}$ telomeric region showed extensive concordance between the affected subjects in these families (fig 2). Concordance was shown in seven of the eight additional families; the markers we used were uninformative in the other family (family 3 ). The tip of the X chromosome long arm, therefore, is concordant in eight of the nine families.

In one available three generation family (family 8), the concordant region is of grandpaternal origin, as in family 1 . In the aunt-niece family (family 4), the father of the affected aunt may be mosaic, so he does not show the disease phenotype. The concordant markers within this region are not shared between the respective families, except for DXS15. The marker DXS15 is the only marker which is concordant among all the seven informative families. Family 6 is only informative for this marker and showed recombination with proximal markers.

\section{Discussion}

While the results in family 1 , the motherdaughter family, are only relevant if Thomas's hypothesis is correct, the results of the concordance study in the other families apply whether or not this proves to be so. If Thomas's hypothesis is correct, our data show that the gene for RS is most likely to be located on the most distal part of $\mathrm{Xq}$, close to the marker locus DXS15. If Thomas's hypothesis is not correct, this region remains an area of highly significant concordance and is therefore still the best candidate region for the RS gene. Furthermore, the telomeric parts of the $\mathrm{X}$ chromosome have not been excluded as candidate regions for RS by other linkage investigations, although these studies use some of the same clinical material. ${ }^{10-12}$

There are several potential candidate genes for RS within $\mathrm{Xq28}$, such as the putative GABA gated chloride channel gene and GABRA3 (the $\alpha 3$ subunit of the $\gamma$-aminobutyric acid receptor which acts as an inhibitory neurotransmitter in the central nervous system).

Because of the difficulty in establishing the underlying pathogenesis of RS, several possible models of its genetic aetiology have been proposed. A two gene model was proposed by Bühler et $a l,{ }^{13}$ which postulated an autosomal locus interacting with an $\mathrm{X}$ chromosome locus.

Because of the limited family material available, other (non-linkage) approaches to identifying and assessing candidate loci are required. Accordingly, we and others have performed candidate gene screening based on clinical data and pathological findings in the RS patients. The genes analysed, bcl-2 (programmed cell death), tyrosine hydroxylase (low dopamine), insulin growth factor 2 (cell growth), dopamine D4 receptor, brain derived neurotrophic factor, and gastric release peptide receptor (disruption of the gene by translocation in a patient with autism), have been completely sequenced for mutations in the coding region and putative promoters and no mutations were identified. $^{14} 15$

Despite the failure so far to have identified an X chromosome gene in which mutations can be shown to be responsible for RS, there is good reason to think that RS is caused by an X chromosome gene defect. Non-random $X$ chromosome inactivation in the leucocytes of affected RS girls has been observed by several groups. ${ }^{16}$ All the available data favour an increased frequency of partial paternal $X$ inactivation. Late $\mathrm{X}$ chromosome replication patterns have been reported in sporadic RS cases. ${ }^{18}$ In this context, therefore, our results strongly suggest distal Xq28 as the most likely location for the RS gene. This applies whether or not the hypothesis of Thomas ${ }^{8}$ about a high male to female ratio of germline mutations proves to be correct.

This study was supported by Axel and Margaret Axson Johnson Foundation, Emil and Wera Cornell Foundation, Ragnar Söderberg Foundation, and the Swedish Medical Research Council (MFR). 
1 Hagberg B, Aicardi J, Dias K, Ramos O. A progressive syndrome of autism, dementia, ataxia, and loss of purposeful heurol 1983;14:471-9.

2 Journel H, Melki J, Turleau C, Munnich A, de Grouchy J. Rett phenotype with X/autosome translocation: possible mapping to the short arm of chromosome X. Am $f$ Med Genet 1990;35:142-7.

3 Zoghbi HY, Ledbetter DH, Schultz R, Percy AK, Glaze DG A de novo X;3 translocation in Rett syndrome. Am $\mathfrak{f}$ Med Genet 1990;35:148-51.

4 Wahlström J, Uller A, Tonnby B, Darnfors C, Martinsson T, Vujic $M$. Congenital Rett syndrome phenotype-deletion short arm chromosome 3. Paper presented at the World Congress on Rett syndrome, Gothenburg, Sweden, 30 August-1 September 1996.

5 Herder GA, Skjeldal O, Hagberg B, Tranebjærg L. Congenital Rett syndrome phenotype-interstitial deletion the World Congress on Rett syndrome, Gothenburg, Swethe World Congress on Rett syndrom

6 Alembik Y, Dott B, Stoll C. Rett-like syndrome in fragile X Alembik Y, Dott B, Stoll C. Rett-like syndrc

7 Easthaugh P, Smith L, Leonard H. Trisomy 21 associated with Rett syndrome phenotype. Paper presented at the World Congress on Rett syndrome, Gothenburg, Sweden, 30 August-1 September 1996.

8 Thomas GH. High male:female ratio of germ-line mutation an alternative explanation for postulated gestational lethality in males in X-linked dominant disorders. $A m f$ Hum Genet 1996;58:1364-8.

9 The Rett Syndrome Diagnostic Criteria Work Group. Diagnostic criteria for Rett syndrome. Ann Neurol 1988;23:425-
10 Ellison KA, Fill CP, Terwilliger J, et al. Examination of X chromosome markers in Rett syndrome: exclusion map-
ping with a novel variation on multilocus linkage analysis. Am $\mathcal{F}$ Med Genet 1992;50:278-87.

11 Curtis ARJ, Headland S, Lindsay S, et al. X chromosome linkage studies in families with Rett syndrome. Hum Genet 1993;90:551-5.

12 Thomas NST, Davies K, Webb T, et al. Molecular genetic studies in familial Rett syndrome. Paper presented at the World Congress on Rett syndrome, Gothenburg, Sweden, 30 August-1 September 1996.

13 Bühler EM, Malik NJ, Alkan M. Another model for the inheritance of Rett syndrome. Am F Med Genet 1990;36: 126-36.

14 Anvret M, Zhang ZP, Hagberg B. Rett syndrome: the bcl-2 gene - a mediator of neutrophic mechanism? Neuropediatrics 1994;25:323-4.

15 Anvret M, Zhang ZP. Current status of genetic research in Rett syndrome. Neuropediatrics 1995;26:88-9.

16 Zoghbi HY, Percy AK, Schultz RJ, Fill C. Pattern of X chromosome inactivation in Rett syndrome. Brain Dev 1990;12: $131-5$

17 Camus P, Abbadi N, Perrier MC, Chery M, Gilgenkrantz $\mathrm{S}$. Chromosome inactivation in 30 girls with Ret syndrome: analysis using the probe. Hum Genet 1996;97: 247-50.

18 Vorsanova SG, Demidova LA, Ulas VY, et al. Molecularcytogenetic and cytogenetic investigations of Rett syndrome in children. Paper presented at the World Congress on Rett syndrome, Gothenburg, Sweden, 30 August-1 September 1996. 